\title{
Metodologias ativas: o uso do team based learning no curso de graduação em música
}

Patrícia Mertzig Gonçalves de Oliveira

Doutora em Educação pelo Programa de Pós-Graduação em Educação da Universidade Estadual de Maringá (UEM). Integrante do Grupo de Pesquisa Educação a Distância e as Tecnologias Educacionais. E-mail: patriciamertzig@gmail.com

\section{Nubia Carla Ferreira Cabau}

Mestre em Educação pela Universidade Estadual de Maringá sob a orientação da prof. Dra. Maria Luisa Furlan Costa... Pesquisadora e membro do grupo de pesquisa GPEaDTEC.E-mail: nubiacabau@bol.com.br

\section{Maria Luisa Furlan Costa}

Doutora em Educação pelo Programa de Pós-Graduação em Educação Escolar da Universidade paulista Julio de Mesquita Filho (Unesp/Araraquara), Líder do Grupo de Pesquisa Educação a Distância e as Tecnologias Educacionais/CNPQ. Endereço Eletrônico: luisafurlancosta@gmail.com 
OLIVEIRA, P. M. G. de; CABAU, N. C. F.; COSTA, M. L. F.. Metodologias ativas: o uso do team based learning no curso de graduação em música. R. Científica UBM - Barra Mansa (RJ), ano XXIX, v. 21, n. 41, 2. Sem. 2019. p. 89-103.

ISSN 1516-4071

\section{Resumo}

O presente texto se configura como um relato de experiência a partir do uso de metodologias ativas em um curso presencial no ensino superior. Para tanto, foi utilizado o Team-Based Learning (TBL) em seis aulas ofertadas presencialmente no curso de graduação em música com habilitação em licenciatura, em uma disciplina de Educação Musical. Nesta disciplina, o conteúdo envolve a leitura, discussão de textos e algumas atividades práticas desenvolvidas pelos estudantes com intuito de serem aplicadas, futuramente, nas aulas de música no ensino básico. Para abordar esse conteúdo, foi utilizado o TBL e verificamos uma participação mais ativa dos estudantes nas aulas, porém com uma baixa compreensão dos conteúdos desenvolvidos em virtude da falta de estudos prévios exigidos pelo TBL.

Palavras-chave: Metodologias Ativas; Team-Based Learning; Educação Musical; Ensino presencial.

\section{Abstract}

This text is configured as an experience report based on the use of active methodologies in a course in higher education. For this, we used Team Based Learning (TBL) in six classes offered in person in the undergraduate music degree with a degree in Music Education. In this course, the content involves reading, discussion of texts and some practical activities developed by students in order to be applied in the future to music classes in elementary school. To address this content, TBL was used and we verified a more active participation of students in class, but with a poor understanding of the contents developed due to the lack of previous studies required by TBL.

Keywords: Active Methodologies; Team-Based Learning; Musical education; Classroom teaching. 


\section{Introdução}

As metodologias ativas são, como o próprio nome diz, modos de se abordar os mais diversos conteúdos nos diferentes espaços educativos e que contam com a efetiva participação dos estudantes. Nessas propostas, os estudantes são protagonistas em sua aprendizagem e podem, individualmente ou em grupo, desenvolverem diversas competências e habilidades para além da aprendizagem específica de um conteúdo e sua aplicabilidade. Como exemplo, destacamos as habilidades de aprender a pesquisar, a selecionar informações relevantes que correspondam a sua busca, a trabalhar em equipe, se envolver com diferentes pessoas e seus pontos de vista, a argumentar porém, ao mesmo tempo, ouvir outros colegas em coletividade.

Dessa forma, destacamos três metodologias ativas que podem contribuir com os processos educativos em diferentes espaços e que já podem ser observadas no Brasil, são elas: o Problem Based Learning (PBL) que significa Aprendizagem Baseada em Problemas, o Team-Based Learning (TBL) ou em português Aprendizagem Baseada em Equipes e as Comunidades de Prática (CoP).

Cada uma delas sugere que os estudantes se envolvam com os conteúdos de uma determinada disciplina de forma ativa, ou seja, são eles que vão integrar com o conteúdo e não mais o professor que será o único responsável por expor esse conteúdo de forma unidirecional e impositiva. As metodologias ativas, então, fazem uso de estudos de caso, resolução de problemas, projetos integradores, entre outros e que podem ter ações individuais ou em grupos de alunos. Essas ações envolvem pesquisa em bibliotecas físicas e virtuais, visitas a diferentes espaços da vida cotidiana (escolas, hospitais, praças, igrejas) e contatos com diferentes profissionais por meio de entrevistas e estágios, além da interação com a comunidade onde vivem os estudantes.

Compreendemos que a proposta das metodologias ativas altera o como fazer para que as demais ações intrínsecas ao conhecimento, ou seja, por que fazer, o que fazer e quais os resultados esperados sejam redimensionadas pelos estudantes no intuito de tomar consciência que a busca pelo conhecimento e sua consequente transformação social depende de seu grau de envolvimento. 
As metodologias ativas são, dessa maneira, um tema que se consubstancia em importante objeto de investigação desenvolvido pelo Grupo de Pesquisa em Educação a Distância e Tecnologias Educacionais (GPEaDTEC) da Universidade Estadual de Maringá, e traz, por meio desse relato, a experiência com o TBL em aulas de educação musical no curso de graduação em música de uma Instituição de Ensino Superior (IES) privada localizada no interior do estado de São Paulo.

Para tanto, o texto aborda o TBL, os procedimentos metodológicos, contextualiza a turma, a disciplina, o conteúdo em educação musical e descreve a sequência de seis aulas em que foi utilizada a metodologia. Realizamos uma breve discussão e reflexão dos resultados obtidos. Nas considerações finais observamos que a utilização da abordagem foi vista como positiva por parte dos estudantes participantes, principalmente no uso da ferramenta virtual que utilizamos para a aplicação de questionário, a página virtual chamada TBL Active (disponível em www.tblactive.com.br).

Do ponto de vista docente, destacamos o aumento significativo da quantidade de acertos às questões apresentadas aos estudantes quando foram resolvidas em grupo, porém pouca capacidade de argumentar sobre o conteúdo abordado. Verificamos também, a dificuldade dos estudantes em realizar as leituras iniciais dentro do prazo estabelecido bem como a compreensão de textos básicos ao conteúdo abordado fazendo com que, nas discussões em grupo, apenas uma minoria de alunos alcançou uma arguição reflexiva ampliando seu conhecimento.

\section{Objetivos}

De forma geral, o presente relato objetiva refletir sobre o uso de metodologias ativas para o ensino de conteúdos de educação musical no ensino superior. Dessa forma pretendemos apresentar o TBL, como uma metodologia ativa possível e inovadora quando aplicada ao curso superior de música. Objetivamos descrever a experiência do uso do TBL em seis aulas de graduação em música, cujo conteúdo envolve o Canto Orfeônico de Villa-Lobos como tema da disciplina de Educação Musical e refletir sobre as possibilidades do uso do TBL no Ensino Superior em Educação Musical sinalizando seus limites e alcances. 
OLIVEIRA, P. M. G. de; CABAU, N. C. F.; COSTA, M. L. F.. Metodologias ativas: o uso do team based learning no curso de graduação em música. R. Científica UBM - Barra Mansa (RJ),

ano XXIX, v. 21, n. 41, 2. Sem. 2019. p. 89-103.

ISSN 1516-4071 


\section{Fundamentação Teórica}

As metodologias ativas não são propostas que partem de teorias inovadoras como muitos acreditam. Dessa forma, o $T B L$ pode ser observado a partir da perspectiva cognitiva que envolve as teorias construtivistas e socioconstrutivistas. Destacam-se autores como Piaget (1896-1980), Vigotski (1896-1934), Dewey (1859-1952) e Bruner (1915-2016). Nessa abordagem, o conhecimento é resultado do processo vivido pelo indivíduo a todo momento, durante toda sua vida e, portanto, não se refere somente à aprendizagem desenvolvida em sala de aula. O ambiente educativo é, assim, o espaço dado aos indivíduos para que experiências de aprendizagem ocorram por meio da interação entre fatores externos e internos que, em processo dinâmico, vão formando o indivíduo. "A preocupação imediata e direta do educador é, então, com a situação em que a interação se processa" (DEWEY, 1976, p. 38).

O TBL é uma metodologia ativa para se trabalhar com os alunos, organizados em equipes, composta por uma sequência de atividades que são divididas em três etapas: o preparo, a garantia do preparo e a aplicação dos conceitos.

O preparo é o momento de organização individual de cada aluno, em que leituras, estudos e testes são realizados. $\mathrm{Na}$ garantia do preparo, as atividades são realizadas em grupos e o conteúdo é fundamentado nos materiais estudados na etapa anterior. Novamente, nessa etapa, testes são aplicados, no entanto, são debatidos e respondidos em equipe. A etapa da aplicação dos conceitos é a prática dos conteúdos teóricos com a participação de toda equipe. Os testes realizados recebem feedback imediato do professor que acompanha o desempenho dos alunos (KRUG, 2016).

No TBL se faz necessário a presença de um professor que domine os tópicos apresentados, porém não há a necessidade de que o mesmo controle todo o processo dos trabalhos em grupos. Como a figura de um professor não é mais responsável por todo o processo de ensino, somada à ausência parcial e estratégica do mesmo, temos como resultado o desenvolvimento de um aluno incumbido de sua própria formação.

Com o TBL, que tem caráter ativo, existe autonomia (por parte do estudante) no preparo individual que antecede as aulas e todo o processo durante a aula é realizado em grupo, exercitando assim forte interação entre os indivíduos. Nessa metodologia, a figura do professor em sala de aula, deixa de ser a de detentor do saber e se torna a de 
facilitador do processo de conhecimento. O responsável pelo aprendizado se torna, portanto, o próprio estudante. $\mathrm{O}$ conhecimento então deixa de ser momentâneo ou restrito ao ambiente escolar e passa a ser integrado e aplicado no cotidiano do estudante.

Destacamos também quatro pilares do TBL apresentados e discutidos por Sweet e Michelsen (2012, p.7, Trad. nossa) com fundamentais para o desenvolvimento dessa metodologia: 1) Uma atitude de pensamento crítico; 2) A capacidade de usar habilidades específicas de pensamento crítico; 3) A capacidade de aplicar essas habilidades em novos contextos; 4) Hábitos de reflexão sobre o próprio pensamento.

O TBL envolve também a avaliação por pares. Essa etapa ocorre ao final de todo o processo o qual os estudantes vão avaliar cada um dos membros de sua equipe. A princípio, essa é reconhecidamente uma tarefa difícil pois o objetivo não é "apontar dedos" mas sinalizar o que foi feito e o que ficou a desejar por cada um dos membros da equipe. Dessa forma, avaliar o próprio processo coletivo também colabora na formação dos estudantes pois já foi incentivado a autonomia na organização do trabalho em grupo o que torna a avaliação por pares também parte significativa do conjunto de atitudes e que o próprio grupo precisa aferir.

Os “métodos ativos” também são recorrentes na literatura da Educação Musical. Esses métodos foram desenvolvidos no início do século XX, na Europa em contexto de guerra. Nesse sentido, o que motivou tal proposta foi acreditar que a música auxiliaria na reconstrução cultural dos países devastados pela guerra. Assim, a música precisaria sair dos espaços exclusivos dos conservatórios privados e adentrar na escola para que mais pessoas pudessem aprender sobre essa arte de forma a restaurar a cultura que foi perdida (OLIVEIRA; COSTA, 2018).

Assim, muitos métodos ativos foram propostos por compositores e postulavam conteúdos baseados no folclore de seu país. Outra característica que diferencia bastante esses métodos se comparados ao ensino de música nos conservatórios é a ausência do instrumento musical. Não se ia mais para a escola ensinar piano ou violino e sim para musicalizar, por meios de jogos lúdicos, atividades de escuta e percepção além de vivências envolvendo música e movimento, crianças de diferentes idades tinham acesso à música em atividades realizadas com turmas de até 40 alunos.

O termo ativo se refere então à participação efetiva dos educandos nesses jogos a partir de seu fazer musical por meio da imitação e da criação. Nesse contexto do início 
do século XX, esses métodos foram desenvolvidos por Karl Orff, Shinichi Suzuki, Edgar Willems, Zoltan Kodaly, Émile Jaques-Dalcroze entre outros, e utilizaram a estética musical da Idade Moderna que privilegia a métrica e a altura definida. Dessa forma, eles podem ser observados como pertencentes à primeira geração de autores em educação musical, classificação esta adotada por Fonterrada (2008). Para a autora, a segunda geração trata de abordagens metodológicas (não mais métodos fechados) que envolvem a estética da música contemporânea e são mais integrados à escuta e, de forma ou de outra, caminham para a superação da representação mental em música legitimando a experiência corporificada e situada.

Nesse sentido, destacamos que a proposta de Villa-Lobos enquanto conteúdo do presente relato situa-se na ordem dos métodos da primeira geração, com forte influência dos modelos europeus e também com uso do folclore no sentido de instaurar no país um sentimento nacional. O Canto Orfeônico foi prático pois os estudantes estavam sempre cantando e solfejando músicas com letras ufanistas durante as aulas. Isso porque VillaLobos foi convidado por Getúlio Vargas, na década de 1930, a colaborar com a formação de uma identidade nacional. Sua importância para os estudos na área de educação musical residem no fato de ser uma proposta pensada para a Educação Básica e que atingiu uma quantidade significativa de estudantes, principalmente nos estados de São Paulo e Rio de Janeiro.

\section{Procedimentos Metodológicos}

O presente texto trata de um relato de experiência ocorrido com uma turma do curso de graduação em música em disciplina que envolve conteúdos de Educação Musical. O levantamento bibliográfico prioriza por textos que abordem o assunto de forma contextualizada com o tema proposto. Os autores selecionados e seus pontos de vista encaminharam a discussão de forma a possibilitar a reflexão, sinalizando seus limites e alcances quando abordados no contexto da educação musical. Para tanto, selecionamos o TBL e o conteúdo musical do Canto Orfeônico proposto por VillaLobos no início do século XX no Brasil. Nas referências bibliográficas destacamos 
OLIVEIRA, P. M. G. de; CABAU, N. C. F.; COSTA, M. L. F.. Metodologias ativas: o uso do team based learning no curso de graduação em música. R. Científica UBM - Barra Mansa (RJ),

ano XXIX, v. 21, n. 41, 2. Sem. 2019. p. 89-103.

ISSN 1516-4071

Oliveira e Costa (2018), Fonterrada (2008) e Fucci-Amato (2012) para contextualizar o modelo orfeão e Krug (2016) para compreendermos a proposta do TBL. 


\section{Apresentação e discussão dos resultados}

O TBL foi escolhido dentre as metodologias ativas para abordar o conteúdo do método do compositor brasileiro Heitor Villa-Lobos no curso de graduação em música para estudantes matriculados no segundo ano do curso. Nessa turma há 34 estudantes, sendo 10 mulheres e 24 homens, com faixa etária de 19 a 37 anos. Grande parte desses estudantes possui bolsas de estudo, já que se trata de instituição privada. Localizada no interior do estado de São Paulo, o curso de graduação em licenciatura em música é noturno e forma profissionais para atuar como músicos e professores de música nos contextos formais, não formais e informais de ensino.

A utilização do TBL levou uma sequência de 6 aulas, sendo cada encontro de duas horas semanais. Para tanto, iniciamos com a apresentação do tema, uma pesquisa inicial seguida da leitura de textos, a resolução de questionário de forma individual e posteriormente coletiva, o momento de arguição dos participantes, a exposição do conteúdo pela professora e as reflexões coletivas de encerramento do tema.

A apresentação do tema ocorreu na primeira das seis aulas. Nela, a turma foi dividida em quatro grupos e cada um dos grupos recebeu uma palavra-chave para realizar uma rápida busca na internet utilizando os aparelhos celulares. As palavraschave de cada grupo envolviam uma possibilidade de discussão sobre o compositor Villa-Lobos. Assim as palavras-chave eram "Villa-Lobos educador", "Villa-Lobos compositor", "Villa-Lobos e seu contexto histórico" e "Villa-Lobos biografia". A partir da busca em páginas virtuais na internet, os grupos explanaram a todos sobre as informações coletadas. Com elas, foi possível dialogar e ampliar as informações trazidas por eles de forma a localizar na proposta metodológica do Canto Orfêonico o conteúdo das próximas aulas. Assim, foi solicitado a leitura de dois capítulos do livro "Escola e Educação Musical: (des)caminhos históricos e horizontes” de Rita Fucci-Amato (2012).

A leitura do texto foi solicitada para que, na aula subsequente, os estudantes fossem capazes de responder a um questionário com 10 perguntas criadas pela professora. Para tanto, o questionário continha 4 alternativas para cada uma das questões e foi utilizado o sitio www.tblactive.com.br. Essa plataforma foi desenvolvida 
exclusivamente para utilizar o TBL por meio de cadastro com login e senha. O professor pode elaborar seu questionário e optar pelo número de alternativas.

Nesse modelo, o estudante não escolhe uma única alternativa e sim, faz apostas cujo limite é a quantidade de alternativas possíveis. Se ele tiver certeza da resposta correta, pode apostar quatro pontos na alternativa de sua escolha desde que o questionário tenha quatro alternativas. Se foram cinco, o estudante tem que apostar cinco pontos em uma resposta ou distribuir seus pontos em outras alternativas. Para que os estudantes acessem o questionário, é solicitado que entrem na página do tblactive e com um simples cadastro com o nome (para que o professor possa reconhecê-los posteriormente no sistema) cada um é convidado a entrar na sala por meio de um número disponibilizado pelo professor.

Conforme os alunos entram, o professor é capaz de visualizar em sua tela a presença e ausência de cada um dos alunos e pode aguardar o acesso de todos. Para começar o questionário, os comandos da plataforma são simples e de fácil manuseio. $\mathrm{O}$ professor acompanha o desempenho de cada um pois a plataforma utiliza cores para os acertos (verde), erros (vermelho) e para as apostas que, quando o estudante aposta parte de seus pontos na resposta correta, a questão aparece na cor laranja para o professor.

Ao finalizar o questionário, encaminha-se para a segunda parte da aula em que os estudantes se unem em pequenos grupos para responder o mesmo questionário novamente. Nesse momento, apenas um dos integrantes acessa a sala e nomeia sua equipe. Depois que todas as equipes estão inseridas na sala, é liberado o início do questionário pelo professor. Nessa nova rodada, há uma discussão sobre a resposta correta pois compreende-se que, em equipe, as chances de acertos às questões são maiores. Após todas as equipes finalizarem seus questionários, o professor encerra a tarefa e a plataforma lhe envia tabelas com porcentagens de erros e acertos, individuais e coletivos, que podem ser utilizados pelo professor como uma forma de atribuir uma nota.

Ao executarmos toda essa ação descrita acima, observamos que individualmente, a maioria dos estudantes não acertou grande parte das questões. Dos 34, apenas três acertaram 90\% das questões e mais de 50\% da turma erraram grande parte das questões. Quando seguimos para a rodada em equipes, percebemos que houve discussão sobre as 
alternativas e $99 \%$ dos times acertaram todas as questões. Toda essa atividade ocupou quatro aulas seguidas.

$\mathrm{Na}$ semana seguinte foram retomadas algumas questões apresentadas no questionário e que, na etapa individual, tiveram poucos acertos. Por meio de aula expositiva, a professora trouxe argumentos a partir do texto base e de outros textos de forma a ampliar a discussão do conteúdo provocada pelo questionário. Essa aula também funcionou como uma revisão a uma avaliação que ocorreria na semana seguinte.

De forma geral, os estudantes gostaram muito da abordagem do TBL e muitos gostariam que as avaliações ocorressem dessa forma. Quando questionados pela metodologia adotada, a resposta foi positiva na totalidade da turma. Porém, pudemos observar aspectos positivos e negativos que, nessa reflexão, acreditamos ser útil para ampliar algumas discussões sobre o uso do $T B L$ e outras metodologias ativas.

Em primeiro lugar, grande parte dos estudantes, quando solicitada a pesquisar utilizando palavras-chave na internet, acessa o primeiro link que surge reduzindo a busca e agilizando a tarefa. Ao entrar em páginas virtuais como o wikipedia, por exemplo, a maioria dos estudantes não faz a leitura da informação na íntegra e não se interessa por entrar nos demais hiperlinks sugeridos pela página.

Em nosso ponto de vista, isso ocorre pelo fato do curso ser noturno e grande parte dos estudantes trabalhar durante todo o dia. O engajamento tão esperado por parte dos alunos ao usarmos o TBL acaba não ocorrendo em sua forma mais ampla. A leitura do texto para a aula seguinte também inexiste. Nessa experiência, apenas dois estudantes de uma turma de 34 alunos leram todo o texto solicitado. A essa questão, verificamos o baixo índice de acerto na etapa individual.

No momento coletivo, muitos estudantes também demonstraram pouco interesse para a resolução do questionário. O que pudemos verificar é o empenho de dois ou três alunos por grupo para resolver as perguntas. A etapa de argumentação, que deveria ocorrer logo após a realização da resolução coletiva, também não ocorreu. Como grande parte dos estudantes não fez a leitura inicial, não havia como realizar uma pequena arguição.

$\mathrm{Na}$ aula expositiva, a maioria dos estudantes foi capaz de compreender a argumentação sobre as respostas corretas e o motivo pelo qual as outras alternativas estavam incorretas, mas não foram capazes de estabelecer relações do conteúdo com 
outras dimensões ligadas ao tema como, por exemplo, a política (no caso o Governo de Getúlio Vargas e o processo de criação de uma identidade nacional), a cultura ( o canto orfeônico com objetivo de civismo evidenciando um caráter ideológico), a sociedade (com suas lutas de classe e relações de poder), a economia (processo de industrialização do país), além de aspectos ligados a educação como a inserção da música na escola e o método do Canto Orfeônico em si, que privilegiou a imitação, o canto e o solfejo, ao contrário de práticas artísticas mais criativas que já estavam na pauta da discussão a partir do movimento da Semana de Arte Moderna de 1922 e dos próprios métodos ativos em educação musical anteriormente apresentados.

$\mathrm{Na}$ avaliação, realizada na aula seguinte, muitos estudantes demonstraram dúvidas que vão desde a compreensão do enunciado até dificuldades na escrita de questões dissertativas. $\mathrm{O}$ que podemos sinalizar como positivo foi o momento coletivo em que os alunos mais engajados de cada um dos grupos explicaram aos demais o que estava sendo perguntado e o motivo pelo qual tal resposta era a correta.

Finalizando, concordamos com Pischetola e Miranda (2019) quando afirmam que as metodologias ativas não podem ser vistas como solução dos problemas educativos e que os conteúdos, para serem abordados de forma contextualizada, historicizada e crítica necessitam de um maior esforço e dedicação de grande parte dos estudantes. A nosso ver, os cursos de licenciatura, quando autorizados a funcionar no período noturno, abrem precedentes a uma formação destituída de tempo para que o conhecimento seja realmente aprendido pelo aluno. Isso porque, ao trabalhar durante o dia, o estudante chega cansado para estudar e não costuma realizar tarefas fora do horário de aula, incluindo aí a leitura dos textos indicados pelo professor.

\section{Considerações Finais}

Imaginamos, ao aplicar o $T B L$, que alguns problemas encontrados em muitas classes de graduação do período noturno pudessem ser superados como, por exemplo, a falta de leitura. Isso porque um estudante poderia aprender com os colegas e estabelecer algumas conexões com o conteúdo a fim de que pudesse coletivamente construir o conhecimento. Porém, isso ocorreria se apenas uma minoria não fizesse sua lição de casa. O que ocorreu nessa turma especificamente foi que, sem a leitura dos textos não só 
da disciplina em questão mas também de outras disciplinas do curso, não foi possível que as reflexões originadas pela aplicação do TBL dessem um salto qualitativo para a aprendizagem e transformação desses estudantes. Apenas uma minoria foi capaz de compreender, argumentar e estabelecer relações sobre o conteúdo aprendido com outros conhecimentos adquiridos. Dessa forma, inferimos que o problema não está no TBL e sim na falta de tempo para a realização das leituras que dariam o necessário aporte ao método.

Cogitamos que a falta de familiaridade ocasionada pelo pouco uso das metodologias ativas, como o TBL, também possa ter contribuído para que o desempenho dos alunos não alcançasse os propósitos esperados, o que nos aponta para outras reflexões como: os nativos digitais usam todo o potencial das Tecnologias da Informação e Comunicação (TIC) para a produção de conhecimento, já que dominam essas tecnologias de forma, muitas vezes, superior aos seus professores que não são desta época? A necessidade da leitura fica mais evidente com o TBL fazendo com que, dessa forma, os próprios alunos percebam que não alcançarão o desenvolvimento desejado para um curso superior se não realizarem estudos que levem à interpretação, compreensão e, para além disso, à decodificação dos textos a fim de que se tornem aptos a entender, criticar e transformar a realidade que os cerca?

Por outro lado, precisamos repensar as metodologias e recursos didáticos utilizados com os estudantes noturnos, para que diante da necessidade de exercer uma atividade no mercado de trabalho, não sejam prejudicados pela indisponibilidade de tempo para uma efetiva participação na sua formação acadêmica.

Sabemos que tais questões evidenciam a necessidade de mais pesquisa na área, de forma que, tais apontamentos, servirão de bases para nossas futuras reflexões. O que podemos afirmar até o presente momento é que o $T B L$, apesar das limitações apresentadas neste relato, mostrou-se como uma ferramenta importante e, principalmente, de grande aceitação por parte dos alunos, mesmo que sua aplicação não tenha alcançado as expectativas para o momento. 


\section{Referências}

DEWEY, J. Experiência e Educação. Tradução de Anísio Teixeira. 2.ed. São Paulo:

Ed. Nacional, 1976.

FONTERRADA, M. T. de O. De tramas e fios: um ensaio sobre música e educação. $2^{\circ}$ ed. São Paulo: Editora UNESP, 2008.

FUCCI-AMATO, R. Escola e Educação Musical (des)caminhos históricos e horizontes. Campinas, SP: Papirus, 2012.

KRUG, R. de R. O "Bê-Á-Bá" da Aprendizagem Baseada em Equipe. Revista Brasileira de Educação Médic $a$, vol.40, n.4, pp.602-610, 2016.

OLIVEIRA, P. M. G. de; COSTA, M. L. F. Mapeamento da pesquisa em Educação Musical a Distância no Brasil. Curitiba, PR: Editora CRV, 2018.

PISCHETOLA, M.; MIRANDA, L. T. de. Metodologias ativas: uma solução simples para um problema complexo? Revista Educação e Cultura Contemporânea. v. 16, n. 43, p. 30-56, 2019.

SWEET, M.; MICHAELSEN, L.K. Critical Thinking and Engagement. In: SWEET, M.; MICHAELSEN, L.K. Team-Based Learning in the Social Sciences and Humanities. Sterling, Virginia: Stylus, 2012. 